\title{
TPMT*V2 Allele
}

National Cancer Institute

\section{Source}

National Cancer Institute. TPMT*V2 Allele. NCI Thesaurus. Code C46061.

Human TPMT*V2 allele is a variant form of the TPMT Gene (TPMT Family), located at chromosome 6p22.3, which encodes Thiopurine S-Methyltransferase. Some TPMT alleles contain variable numbers of 17/18 bp tandem repeats (VNTR), within the GC-rich 5 '-flanking TPMT promoter region that modulate the level of TPMT enzyme activity (to a smaller extent than ORF-based SNP effects). TPMT *V2 contains 2 VNTR. A decrease in gene expression is seen with increasing repeat numbers. 